\title{
Construction and Implementation of Teaching Quality Evaluation and Performance Assessment System on Engineering Training
}

\author{
Hai-guang ZHANG, Qing-xi HU, Lan-lan HE * \\ National Demonstration Center for Engineering Training Shanghai University \\ Shanghai China
}

\begin{abstract}
National demonstration center for engineering training is an important public practice teaching platform of training college students. The teaching quality is directly related to the cultivation of students' engineering and innovating ability. However, It has not been effectively evaluated. This paper constructs a method of evaluation system of the teaching quality, which is called "Stereoscopic -Double Cycle" system. By trying to link the quality with the performance assessment, it has changed the former situation that engineering training teaching only paid attention to quantity, but not quality. And it greatly promoted the teaching level of the engineering training teachers. The cultivation of the students' engineering ability and innovating ability are also guaranteed essentially. It's of great significance for cultivating the complex high-quality talents in the present society.
\end{abstract}

Keywords-engineering training; teaching Quality evaluation; performance assessment; Stereoscopic-Double Cycle; engineering ability

\section{INTRODUCTION}

In the background of teaching quality and reforming project for undergraduate courses, China has paid more attention on cultivating students' innovating talents and engineering abilities during the process of constructing "high-level universities". The construction and reform of practical curriculum bring about major breakthroughs in improving the quality of students' engineering and innovating ability.

Engineering technical training center in higher schools is not only the enlightenment for college students to understand engineering, but also the platform for training their innovating ability. So the quality of training teaching is the key to make substantial progress in the reform of engineering training courses. It is necessary to construct the evaluation system of practice teaching oriented to engineering training and draw up effective indicators, exploring the significant combination of engineering training teaching quality . Performance assessment is an important way to improve the overall of that.

\section{OVERVIEW AT HOME AND ABROAD OF TEACHING QUALITY EVALUATION IN COLLEGES AND UNIVERSITIES}

The evaluation of teaching quality has been paid more attention by foreign universities, and there are many different

Education Reform Project of Engineering Training by Ministry of Education(No. JJ-GX-JY201735); Education reform project of Shanghai university: the construction of curriculum of engineering practice and talent cultivation mode related with the competition of college students engineering training ability assessment and evaluation systems according to the characteristics of different universities. Taking universities in USA for example, teaching quality is one of the most important contents of teachers' performance assessment. It is mainly adopted by forms of teachers' self-evaluation, peer review, and students' evaluation. The students' evaluation, which is regarded as the key indicators must be simply understood by students. The evaluation results are directly related to the employment performance and promotion of teachers in some universities $^{[1-2]}$. There have been many explorations in practice teaching quality system, practice teaching indicators and scoring standards in domestic colleges and universities, certain results have been achieved ${ }^{[3-4]}$. As an important platform for practical teaching, the hardware facilities are improving step by step, but the connotation construction still at a certain stage in the exploration, which focused only on teaching system and staff, curriculum structure, etc, there are still some gaps between with foreign universities. So, many scholars and managers have also launched research on the management of the center. A lot of innovations have been made in reforming experimental teaching mode to establish assessment system ${ }^{[5-6]}$. However, this evaluation is basically adopted by the form of random attendance mode of supervisory group or expert group, the construction of their own practice teaching quality evaluation system is still not mentioned, so many problems have arisen, such as single evaluation subject, random indicators, fewer results feedback, imperfect incentive policies and so on ${ }^{[7]}$. And it is not correlated enough with teacher's performance distribution, professional title assessment and promotion, so far they've had little effect on improving the teaching quality.

\section{CONSTRUCT THE "STEREOSCOPIC - DOUBLE CYCLE" EVALUATION SYSTEM OF TRAINING TEACHING QUALITY}

Under the current situation of paying more attention to quantity than quality, engineering training teaching performance evaluation is merely a formality, so a "Stereoscopic-double cycle" teaching quality evaluation system is constructed and a series of performance evaluation systems linked with teaching quality are set up. Through bold reform, we could really achieve the purpose of finding out the shortcomings and promoting the improvement of the assessment. The engineering training teaching evaluation team is no longer composed of leaders, but all the staff of the center. So that we could strengthen the sense of responsibility of all 
staff of the center, improve teachers' awareness of the quality. Then we'll make the whole staff of the center attach importance and pay more attention to the quality of engineering training teaching. Therefore, the teaching evaluation system of "Stereoscopic and double-cycle" is constructed.

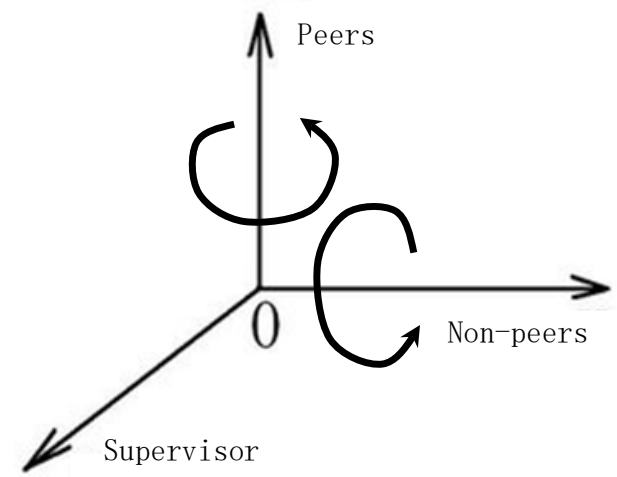

Fig. 1. "Stereoscopic - Double Cycle" system

\section{A. "Stereoscopic"}

"Stereoscopic" evaluation is a comprehensive evaluation from three dimensions (Fig.1), including peer evaluation (teachers of the same engineering training teaching project), non-peer evaluation (teachers of different engineering training teaching projects), supervisory evaluation (experienced engineering training teachers, central and department leaders, etc.).

Peer evaluation is conducted by inspecting each other, which not only helps inspectors to learn the teaching experience from other engineering training teachers, but also evaluates the teachers' design, methods and means of professional teaching correctly. Non-peer evaluation not only learns from each other but also evaluates the ideas of practical teachers and highlights the links in the training courses. The supervisory evaluation is to evaluate the teachers' teaching skills, teaching attitudes, and understanding of teaching materials. Under this supervisor, Teachers should prepare equipment and fixtures, practical materials and organization.

\section{B. "Double Cycle"}

The "double cycle" operation mode aims at peer evaluation and non-peer evaluation, that is, to take the form of circular inspection in these two dimensions, so as to avoid the transaction between the inspector and inspected person, in order to make the evaluation results more objective and authentic (Fig.2).

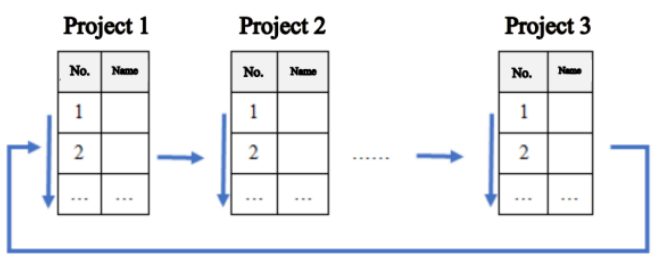

Fig. 2. Sketch of "Double Cycle" inspection

\section{Quality EVAluation INDEX AND PERFORMANCE} APPRAISAL METHOD OF EDUCATIONAL REFORM PROJECTS

\section{A. Teaching quality evaluation index and its weight}

As the core of the construction of "Stereoscopic - Double Cycle" quality evaluation system, the teaching quality evaluation index is the vane of it and the key to success. Therefore, it should be able to objectively and impartially evaluate the whole process of engineering training teaching and contains the content of index, the quantitative operation degree, the weight of index, etc. It should be also considered comprehensively in combination with the actual situation of the unit, which is helpful to ensure the effectiveness of the evaluation results ${ }^{[3]}$. According to the said situation of our department, the teaching quality evaluation index of three-level engineering training is worked out. The first level index mainly includes 6 items (Expressed in $A_{1}-A_{6}$ ), including basic requirements, practice safety, practice content, teaching tools, teaching method and teaching skills. The second level index mainly includes 18 items(Expressed in $\mathrm{A}_{\mathrm{ij}}$, $\mathrm{i}=1 \sim 6$ ), such as material and instrument preparation, neat dress, environmental hygiene and so on, and the third level index mainly includes 46 items of material preparation, clean and tidy classroom environment, teaching progress and so on (one of the six items is as shown in table 1).

Engineering training teaching quality grade $\mathrm{A}$ is shown as below:

$$
\mathrm{A}=\sum_{i=1}^{6} A_{i}
$$

Among the first-level index, the index $A_{1}$ is the most basic requirement of engineering training teaching, and contains more second and third-level indexes, but all of them are necessary items. In order to arouse the attention of training teachers, the interrelation of all the indexes is "and", that is, any index that does not meet the requirements is 0 .

$$
\begin{aligned}
& A_{1}=A_{11} \cap A_{12} \cap A_{13} \cap A_{14} \cap A_{15} \cap A_{16} \\
& =\left\{\begin{array}{c}
0 A_{1 i} \text { Not up to the mark; } \\
0.2 A_{1 i} \text { Meet all requirements. }
\end{array}\right.
\end{aligned}
$$

The second and third level indexes contained in the other five first-level indexes are all parallel, and their weights are confirmed according to the degree of importance, which also reflects the emphasis of engineering training and teaching. 
TABLE I. THREE LEVELS OF INDEXES OF ITEM A1

\begin{tabular}{|c|c|c|}
\hline Level 1 & Level 2 & Level 3 \\
\hline \multirow{11}{*}{$\begin{array}{c}\mathrm{A}_{1} \\
\text { basic } \\
\text { requirements } \\
(0.2)\end{array}$} & \multirow{2}{*}{$\begin{array}{c}\mathrm{A}_{11} \text { Material and } \\
\text { instrument } \\
\text { preparation }\end{array}$} & $\begin{array}{l}\text { A } 11 \text { Material } \\
\text { preparation }\end{array}$ \\
\hline & & $\begin{array}{c}\mathrm{A}_{112} \text { instrument } \\
\text { preparation }\end{array}$ \\
\hline & \multirow{2}{*}{$\begin{array}{c}\mathrm{A}_{12} \text { neatly } \\
\text { dressed }\end{array}$} & $A_{121}$ Work clothes \\
\hline & & $\mathbf{A}_{122}$ Wear badges \\
\hline & \multirow{2}{*}{$\begin{array}{c}\quad \mathbf{A}_{13} \\
\text { environmental } \\
\text { health }\end{array}$} & $\begin{array}{c}A_{131} \text { The classroom } \\
\text { health }\end{array}$ \\
\hline & & $\begin{array}{l}A_{132} \text { practical } \\
\text { environment }\end{array}$ \\
\hline & $\begin{array}{l}\mathrm{A}_{14} \text { Arrive at the } \\
\text { classroom early }\end{array}$ & $\begin{array}{l}A_{141} \text { Arrive at the } \\
\text { classroom early }\end{array}$ \\
\hline & \multirow{2}{*}{$\begin{array}{l}\mathrm{A}_{15} \text { The outline } \\
\text { requirements }\end{array}$} & $A_{151}$ teaching objectives \\
\hline & & $A_{152}$ teaching progress \\
\hline & \multirow{2}{*}{$\begin{array}{l}\mathrm{A}_{16} \text { Teaching } \\
\text { requirements }\end{array}$} & $\mathrm{A}_{161}$ elected content \\
\hline & & $\mathrm{A} 1_{\sigma_{2}}$ elected books \\
\hline
\end{tabular}

\section{B. Performance assessment methods}

The evaluation results of teaching quality according to the above engineering training quality evaluation indexes are reflected in the workload of undergraduate engineering training teaching. This means the results are directly linked to the performance assessment. So, it greatly attracts all the staff to pay more attention to their teaching quality. If a teacher's average performance scores in trial class do not reach the average level of all engineering training teachers, his workload of teaching will be discounted on the basis of the actual workload, and vice versa.

The average scores of the teachers given the trial class are normalized to obtain the quality coefficient of the teachers, finally, the equivalent engineering training workload of them is obtained. this workload is included in the evaluation, promotion and performance of the center.

The teaching workload of equivalent engineering training is as follow:

$$
W_{e}=W_{a} \times \mathrm{Q}=W_{a} \times \frac{\sum S_{a i}}{N_{b}}=W_{a} \times \frac{1}{N_{b}} \times \sum \frac{\sum S_{e j}}{N_{e}}
$$

Where, $W_{e}$ is equivalent engineering training teaching workload (hours); $W_{a}$ is the teaching workload of practical engineering training (hours); $\mathrm{Q}$ is the mass coefficient; $S_{a}$ is the average score ( $\left.\mathrm{i}=1,2,3 \ldots, N_{b}\right)$, and $N_{b}$ is the number of students attended; $S_{e}$ is the evaluation result of engineering training teaching for a certain engineering training teacher $(\mathrm{j}=$ $1,2,3 \ldots, N_{e}$ ), and $N_{e}$ is the number of evaluators.

\section{Implementation effect}

Engineering training teaching quality evaluation is not for the purpose of rewards and punishments, but the formation of practical incentive and competitive mechanism of the engineering training teaching quality. This can greatly improve it. It also mobilizes the full sense of responsibility and enthusiasm and then make whole staff realize the importance of engineering training teaching.

In the past, the teaching level of engineering training was not valued, many practical projects and contents were out of date, and the teaching methods have remained unchanged for a long time. It is implemented the comprehensive quality assessment system in our engineering training center, especially linked between the teaching quality and annual assessment, teaching quality has undergone great changes. Engineering training teachers make full use of all kinds of modern teaching skills, and learn the experience of other teachers. This provides strong support for the subject competition. We have won more than 30 Shanghai and national awards in the undergraduate engineering training discipline competition for several years.

\section{CONCLUSION}

In short, through the construction of engineering training teaching quality evaluation system and the specific evaluation index, the atmosphere of the whole center has been initially formed by closely integrated with performance assessment. It helps to keep pace with the construction of high-level universities.

Although the "Stereoscopic-Double Cycle" evaluation system has been preliminarily explored and achieved certain results. The rationality of this system and indicators still need to be improved in practice. Though students' evaluation of teaching conducted in the past was not suitable for evaluation, it's still necessary to explore the student-centered teaching quality evaluation system further, students are always the foundation. We should construct the evaluation indicators which are closed to the students so that the students can easily grasp the evaluation indicators to meet and fit the needs of cultivating innovative talents in high-level universities.

\section{REFERENCES}

[1] Xuemin Chen, Lingling Qi. Teaching quality assessment and teacher performance assessment at the University of Minnesota [J]. China Higher Education Evaluation, 2007.4:75-77.

[2] Jing Li. The characteristics and enlightenment of the evaluation Index system of teaching quality in American colleges and universities [J]. Heilongjiang Researches on Higher Education, 2009, 187(11):96-98.

[3] Li Kang, Jie Chen. A Study on the relationship between the stress of teaching quality assessment and the willingness to improve teaching performance [J]. Higher Education Exploration, 2017, (6):56-60.

[4] Chidi Hu, Yan Yan. Performance Evaluation Promoting Quality Guarantee : Practice on the Construction of Ningbo Higher Education Quality Guarantee System [J]. China Higher Education Research, 2017, (12):67-70.

[5] Lin Yan, Zhanjun Mu. Research in the Evaluation of College Teachers' Teaching Quality based on $360 \sim^{\circ}$ Feedback [J]. The Guide of Science \& Education, 2012, (2):146-147.

[6] Jianjun Zhang, Zhijian Zhang, Zhongqin Ge et al. Grasping opportunity of innovative and entrepreneurial era and enhancing construction connotation of demonstration center [J]. Experimental Technology and Management, 2017, 34(3):206-209.

[7] Hongmei Cai, Xiaodong Xu. Construction of Quality Evaluation System of Classroom Teaching in Colleges and Universities [J]. Researches in Higher Education of Engineering, 2014, 3:177-180. 